International

Medical Society

http://imedicalsociety.org

\title{
Body perception of cocaine users
}

ORIGINAL

Manuela Carla de Souza Lima Daltro1, Luciene de Oliveira Marinho², Ellen Lima Xavier ${ }^{3}$, Tâmara de Araújo Costa ${ }^{3}$, Erica Martins de Freitas ${ }^{3}$, Humberto Medeiros Wanderley Filho ${ }^{3}$, Juliane de Oliveira Costa Nobre ${ }^{4}$, Viviane Valeria de Caldas Guedes Garcia ${ }^{5}$, Mayara Leal Almeida Costa ${ }^{6}$, Polianne Medeiros Brito7, Aucélia Cristina Soares de Belchior ${ }^{8}$, Rosangela Maria Fernandes de Oliveira ${ }^{9}$, Karini Vieira de Menezes Omema ${ }^{10}$, Michelle Bacurau Trajano Rodrigues ${ }^{11}$, Murilo Nunes de Magalhães ${ }^{12}$, Nicoly Negreiros de Siqueira Mariano ${ }^{13}$, Elicarlos Marques Nunes ${ }^{14}$

\section{Abstract}

Introduction: The use of drugs by man is considered an ancient and universal human practice. The drugs are capable of causing psychotic and psychomotor disorders.

Objective: It aimed to assess body perception of cocaine users in a city of high backlands of Paraiba.

Methods: This is a research in applied type with a quantitative approach. The study population involved drug users treated at $A D$ Attention Psychosocial Center (Alcohol and drug addicts) in the chosen city. The sample consisted of 18 drug users, 15 males and 3 females, aged from 16 to 49 years, it was applied a sociodemographic questionnaire and Askevold test.

Results: It was observed that there were changes in body perception of cocaine users, prevailing the moderate asymmetry in no more users subjects and very serious in the drug users.

Conclusion: Through this research, it was possible to see that the constant use of cocaine alters the body perception of the users, as the continued use of psychoactive substances causes psychomotor agitation, it is proposed, then, a more comprehensive role of physiotherapy and occupational therapy in these patients, as well as expand the knowledge of the various health professionals on the subject.
1 Physiotherapist. Master in Health Sciences. Teacher of Department Physical therapy*

2. Physiotherapist.

3. Bachelor Graduate of Physiotherapy*

4. Nurse. Master in Health Sciences. Teacher of Department Nursing*

5. Physiotherapist. Master in Public Health. Coordinator and teacher of physical therapy department*

6. Physiotherapist. Master of Science in Education. Teacher, Department of Physical Therapy*

7. Physiotherapist. Master in Public Health. Teacher of Department Physical Therapy*

8. Physiotherapist. Doctor. Teacher of Department Physical Therapy*

9. Physiotherapist. Teacher Department of Physical Therapy*

10. Occupational Therapist. Teacher of UNCISAL.

11. Occupational Therapist at Psychiatric Hospital Professor Severino Lopes.

12. Physiotherapist graduated from Maceio Studies Center.

13. Doctor. Department of Medicine*

14. Nurse. Master in Public Health. Teacher of the Department Nursing*

* Of Patos Integrated College (PB), Paraíba, Brazil.

Contact information:

Elicarlos Marques Nunes.

झ elicarlosnunes@yahoo.com.br 


\section{Introduction}

The use of drugs by man began a long time ago. There are archaeological data that suggest alcohol consumption by approximately 6,000 B.C. and is currently considered an ancient and universal human practice. However, from the 1960's, the consumption of substances became a global concern, mainly due to its high frequency and the risks that can lead to health [1-2].

The consumption of these substances usually begins in adolescence, because it is a period in which the individual goes through changes in behavior and personality, they are able to alter neuronal function with consequent modification of the performance of brain function, as well as the whole process of normal thought, sensory perception, attention, concentration, memory, feelings, emotions, motor skills, intellectual level, among others [3-4].

Cocaine is characterized by being a psychoactive substance capable of blocking the reuptake of dopamine in the synaptic cleft, leading to increased dopaminergic neurotransmission and conducting to psychotic and psychomotor disorders [5]. In addition to producing a hyperactive state, pleasure, power, insomnia, decreased appetite, increased heart rate, breathing and blood pressure, fever and hand tremor [6].

With chronic use of cocaine, the subject tends to have psychotic symptoms of paranoid type, and in the presence of the drug, often expresses episodes of psychomotor agitation. Also in withdrawal cases, it occurs phenomena such as psychomotor agitation and fluctuations of mood, characterized by intense anxiety and depressive symptoms [7].

The Brazilian Society for Psychomotor defines the term psychomotor as the science that studies the human being through their body moving and in relation to internal and external environment in which they live. It relates to the ripening process, wherein the body is the origin of the cognitive, emotional and organic acquisitions [8]. The same is intended to see the man in his fullness, and never separate the body, the subject and affectivity [9].

A good psychomotor is based on the ideal performance of the following elements: tone, posture, perception, expression, laterality, global and fine coordination, good balance, body notion and spatiotemporal structure [10].

Based on this context, it is defined as body image the figure of the human body designed in mind. It comprises all the ways that a person experiences and conceptualizes his own body, constituting a singular phenomenon structured in existential and individual experience of man with himself, with others and with the universe [11].

With respect to the body symmetry, states that it corresponds to the degree of similarity between the right and left sides of an individual body [12].

Impairment of psychomotor activity, especially hyperactivity, agitation and dyskinesias type events and dystonias are clinical manifestations associated with cocaine intoxication [13]. Thus, the clinical manifestations, usually associated with disorders of psychotic nature, would have resulted of dopaminergic hyperactivity in various brain pathways where this neurotransmitter plays a central role, of course, in balance with the action of other neurotransmitters. Regions such as the frontal cortex, anterior cingulate gyrus, limbic structures and the connections of these regions with the basal core would be brain areas also frequently implicated in neuropsychiatric disorders caused by cocaine [14].

Noted the correlation of delusions and hallucinations of cocaine users in precipitation of psychomotor disorders [15]. The authors [16] report that addiction can affect self-perception of body image.

This study aimed to evaluate the body perception of cocaine users.

\section{Methods}

The following study, from the point of view of its nature, was framed in applied research with a 
quantitative approach, corresponding to its objectives through a descriptive research. It was chosen as the scenario of this research the AD Psychosocial Attention Center (alcohol and drugs) - CAPS-AD located in a city of high backlands of Paraiba.

The Psychosocial Care Center AD (alcohol and drug addicts) in the chosen city owned 42 cocaine users, but participated in the study 18 cocaine users who agreed to participate.

For inclusion criteria, it was needed to be user of cocaine, be attendet at CAPS AD and being right-handed, and to reverse it was refused to participate the subjects that did not sign the Free and Enlightened consent form. After the consent, by signing the consent form, they were applied to 18 users the sociodemographic questionnaire with questions about: participant identification, occupation and profession and the application of Askevold test done as follows: the individual being evaluated, should be positioned in front of a sheet of craft paper (1.40 $\mathrm{m}$ long and $0.60 \mathrm{~m}$ wide) attached to the wall at a height of $0.40 \mathrm{~m}$ above the ground. Later, with the patient bandaged, it is requested to perform the bending of shoulders (90 degrees) with the elbows extended in order to play the paper in front, to establish a correct distance from the sheet of paper. Thus, once properly positioned, the subject is instructed to imagine that he is in front of a mirror. It is then explained that when the evaluator touch at some point of the body, the individual should mark with a felt-tip pen, a point in the paper corresponding to the point touched.

Thus, every point touched accounts with its representation immediately marked by the individual in the paper. The points touched are: the apex of the head, right and left acromion-clavicular joints, the right and left waist curves (above the apexes of the iliac crests) and the greater trochanter of the right and left femur. With blue pen the patient blindfolded mark the points proposed by the therapist and the black pen follow the points regarding the symmetry of the patient and the red mark the points of the likely symmetry. With the aid of a ruler, it is joined the points made by the person during the Askevold [17] test and a geometric figure is obtained, as shown below.

Figure 1: Perception of body image. Source: ASKEVOLD 1975.

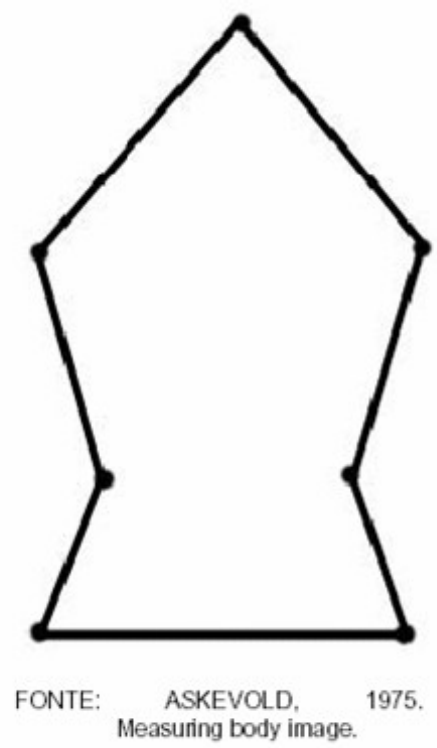

Based on the results obtained, the data were analyzed by means of tables and charts, using Microsoft Excel 2010 version .

As the survey research involved human beings, its protocol was submitted to the Research Ethics Committee (CEP) of the Patos Integrated Colleges (FIP) and approved under number 063/2011.

\section{Results}

\section{Characterizations of Subjects}

The sample consisted of 18 cocaine users, 15 males and 3 females, average age between 16-29 years. Regarding to education, $14(77.77 \%)$ of them had incomplete primary education and 4 (22.23\%) were illiterate, compared to income, $14(77.77 \%)$ had no occupation and 4 (22.23\%) worked in family 
home. With regard to substances used, the users not used only one type of drug. All patients in the CAPS AD felt satisfied with the institution. Of these, $14(77.77 \%)$ are still cocaine users and 4 (22.23\%) do not use for more than 6 months.

\section{Corporal perception}

According to the results obtained by the drawings of participants, performed by Askevold test, it was realized that there are varying degrees of body asymmetry, there is, therefore, a need to develop a classification of body asymmetries, which was used throughout this search. Therefore, asymmetry intervals, according to Chart 1, were determined using as parameter, the highest value found both in users with those who were not cocaine users to a body segment, divided by three.

It were considered very serious, cases impossible to calculate angles.

As regards to the body asymmetry of patients that are still drug users, there is, 14 of the respondents, it was found that 1 (7.14\%) user had body symmetry of the head relative to the shoulders, prevailing the moderate asymmetry in 6 users (42.86\%), and in 5 $(35.72 \%)$ very serious. When viewed the asymmetry of the right shoulder to left shoulder, it was found the same results for light and very serious asymmetry with 5 (35.72\%) participants each. They were observed in relation to the hip, 8 (57.14\%) users with right hip asymmetry against the left as light, but 5 (35.72\%) very serious; and finally the asymmetry of the right trochanter relative to the left, there was a predominance of very serious asymmetry in the total of 5 (35.72\%) participants.

As for participants who no longer used cocaine, there was body asymmetry in 4 (22.23\%) of respondents, it can thus observe the prevalence of moderate asymmetry in 2 (50\%) users in relation to the shoulders; symmetry regarding the right shoulder to the left, one (25\%) users 1 (25\%) light, 1 (25\%) moderate and $1(25 \%)$; moderate asymmetry of the right hip against the left hip 3 (75\%) users; right asymmetry of the trochanter with respect to the left light 2 (50\%) and moderate 2 (50\%) studied.

As Chart 2, it shows that the aspect asymmetry of the head relative to the shoulders, in cocaine users there was a predominance of moderate and extremely serious asymmetry, while former users predominated slight asymmetry; in the aspect asymmetry of shoulders, it was found that in the cocaine users predominated light and very serious asymmetry, and related to former users was found cases of symmetry; as the asymmetry of the hips, cocaine users showed a predominance of light and very serious asymmetry, and as the former users predominated moderate asymmetry, and with regard to the asymmetry of the trochanter, drug users showed a predominance of very serious asymmetry, and in former users were predominantly mild and moderate asymmetry.

Table 1. Body Asymmetries Classification according to the angles.

\begin{tabular}{|c|c|c|c|c|}
\hline \multirow[b]{2}{*}{ ASYMMETRY } & \multicolumn{4}{|c|}{ DEGREES } \\
\hline & Head x shoulders & $\begin{array}{l}\text { Right shoulder } \mathrm{x} \text { left } \\
\text { shoulder }\end{array}$ & Right hip x left hip & $\begin{array}{l}\text { Right Trochanter } x \\
\text { left trochanter }\end{array}$ \\
\hline Light & $1-11$ & $1-6$ & $1-10$ & $1-10$ \\
\hline Moderate & $12-22$ & $6-10$ & $11-20$ & $11-20$ \\
\hline Serious & $23-35$ & $11-15$ & $21-30$ & $21-40$ \\
\hline
\end{tabular}

Source: Research Data, 2016. 
Table 2. Classification of asymmetries of drug users and former drug users patients

\begin{tabular}{|c|c|c|c|c|c|c|c|c|c|c|}
\hline \multirow{3}{*}{ INDICATORS } & \multicolumn{10}{|c|}{ Users and ex-users } \\
\hline & \multicolumn{2}{|c|}{ SYMMETRY } & \multicolumn{2}{|c|}{ Light } & \multicolumn{2}{|c|}{ Moderate } & \multicolumn{2}{|c|}{ Serious } & \multicolumn{2}{|c|}{ Very Serious } \\
\hline & Users & $\begin{array}{l}\text { ex- } \\
\text { users }\end{array}$ & Users & $\begin{array}{l}\text { ex- } \\
\text { users }\end{array}$ & Users & $\begin{array}{l}\text { ex- } \\
\text { users }\end{array}$ & Users & $\begin{array}{l}\text { ex- } \\
\text { users }\end{array}$ & Users & $\begin{array}{l}\text { ex- } \\
\text { users }\end{array}$ \\
\hline $\begin{array}{l}\text { Asymmetry } \\
\text { of the head } \\
\text { against the } \\
\text { shoulders }\end{array}$ & 1 & 0 & 2 & 1 & 6 & 2 & 0 & 1 & 5 & 0 \\
\hline $\begin{array}{l}\text { Asymmetry of } \\
\text { right shoulder } \\
\text { against the left }\end{array}$ & 0 & 1 & 5 & 1 & 3 & 1 & 1 & 1 & 5 & 0 \\
\hline $\begin{array}{l}\text { Asymmetry } \\
\text { of right hip } \\
\text { against the left }\end{array}$ & 0 & 0 & 8 & 1 & 0 & 3 & 1 & 0 & 5 & 0 \\
\hline $\begin{array}{l}\text { Asymmetry } \\
\text { of the right } \\
\text { trochanter } \\
\text { against the left }\end{array}$ & 0 & 0 & 3 & 2 & 4 & 2 & 2 & 0 & 5 & 0 \\
\hline
\end{tabular}

Figure 2: Asymmetry very serious (it was not possible to calculate the angles). Source: Research Data, 2016.

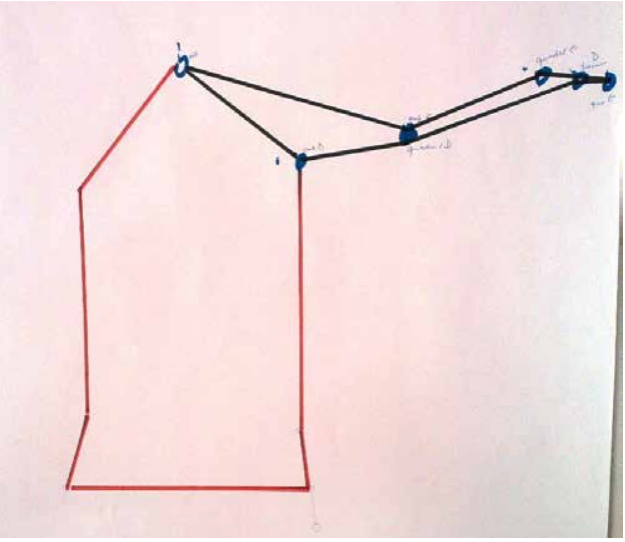

\section{Discussion}

For body perception is considered good, within the acceptable parameters, according to the classification prepared from Askevold guidelines [17], it is necessary that all geometric figure made from the
Figure 3: Asymmetry very serious (it was not possible to calculate the angles). Source: Research Data, 2016.

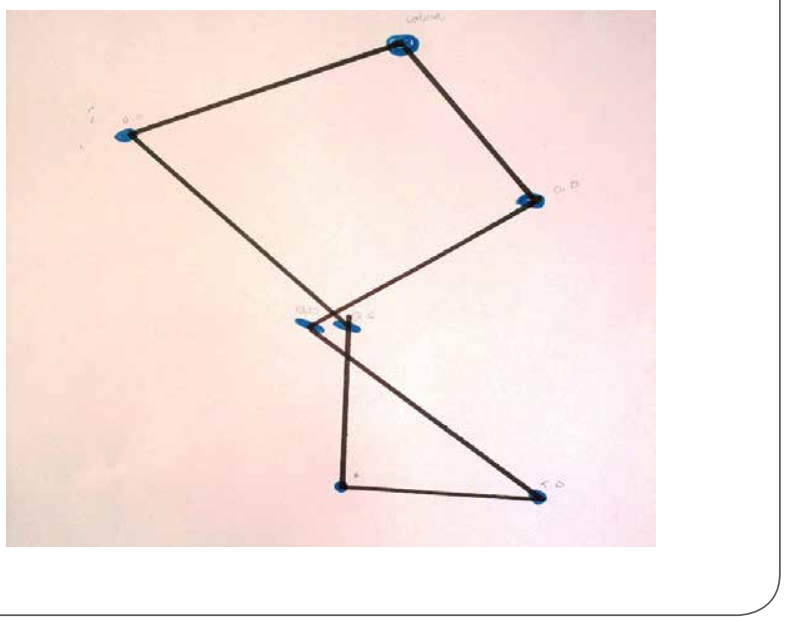

points marked by the individual, must be presented in a symmetrical way.

As regards the body asymmetry patients still cocaine users, most of these individuals had very serious imbalances, while former users prevailed to asymmetries of moderate type. 
The psychomotor agitation in cocaine users due to neurotransmitter imbalance and dopaminergic hyperactivity caused by cocaine. And, in chronic cocaine users, repeated dopaminergic activation adversely affects the inhibitory functions, self-loss and precipitation of behaviors of impulsivity and psychomotor agitation [18-20]. The psychomotor agitation often is associated with mental clutter frames, which can occur both during force of cocaine, as in the withdrawal of the same step [21].

The hypofrontality caused by cocaine and other substances leads to the behavior of the mediated functions by the prefrontal cortex, among them, the organizational skills of cognitive functions and the programming and self psychomotor behavior [22].

The cocaine blocks the reuptake of dopamine in the synaptic cleft of these pathways causing increased dopaminergic neurotransmission and leading to psychotic and psychomotor disorders [5].

Amann-Gainotti (2002), in assessing the internal body image of addicts, noted issues related to self-destruction, search for salvation, body cancellation and paths division [23].

Confirming in his work, by comparing the results obtained with the results of research on body perception of students of $1^{\circ}$ and $8^{\circ}$ physiotherapy period, through Askevold method, it was found that participants with the same age group of this study, there was an increase of angles, since the asymmetry and body awareness in patients who are not cocaine users had no significant changes [24].

Studies indicate that a better body perception is associated with a more physically active standard and better eating habits and without the use of drugs [25-26].

\section{Final Considerations}

Through the present research, it was possible to see that the constant use of cocaine alters the body perception of the users, as the continued use of psy- choactive substances causes psychomotor agitation, mood swings, making them attentive and depressive. From a psychological point of view, physical activity acts positively on self-esteem, body image and satisfaction with life by increasing socialization, functional independence and cognitive function, control of stress, anxiety, depression and consumption of drugs.

It was observed that there were changes in body perception of cocaine users, prevailing moderate asymmetry in patients who are not cocaine users anymore and very serious in even users patients.

With this work, it is proposed to attempt the role of physiotherapy and occupational therapy in these patients of multi and interdisciplinary way. Even though a large study challenge by the scarcity of literature, it was of great importance, however, this is the beginning of a struggle for the implementation of physical therapy in mental health, and also for further studies with larger samples.

\section{References}

1. Tavarez BF, Beria JU. Lima MS. (2001). Prevalence of drug use and school performance between adolescents. Public Health Journal, 35 (2), 150-158.

2. Neto FB. Drugs: Why do people use? Can we prevent? Florianopolis, Insular, 2009.

3. Brusamarello, T .; Maftum, MA .; Mazza, VA .; Silva, AG. (2010). Role of the family and the school in prevention of drug use by teenage student. Cienc.Cuid. Health.

4. Mattos P, Alfano A. Araujo C. (2004) Neuropsychological assessment, In F.kapezinski, J. quevedo, I. Izquierdo (eds.). Biological Basis of Psychiatric Disorders (pp.149-155). Porto Alegre Artmed.

5. Azevedo RCS. Cocaine users and AIDS: a study about risky behavior. 2000. 285f. Doctoral thesis. State University of Campinas, Faculty of Medical Sciences, Campinas, 2000.

6. Siqueira L, Fabri A, Fabri R. Overview, Pharmacological and Toxicological cocaine aspects and its effects on pregnancy. Electronic Journal of Pharmacy v. 8, no. 2, p. 75-87, 2011.

7. Boutros NN, Gelerrnter J, Gooding DC, Cubells J, Young A, Krystal JH, Kosten T. Sensory gating and psychosis vulnerability in cocaine-dependent Individuals: preliminary data. Biological Psychiatry. v.51, n.8, p.683-686, 2002. 
8. Psychomotor Brazilian Association. The Psychomotor. Rio de Janeiro. Available in: www.psicomotricidade.com.br/ apsicomotricidade.htm. Accessed: June 2016.

9. Gonçalves F. From walk to write: a psychomotor way. Sao Paulo: Cultural RBL 2011.

10. Barreto SJ. Psychomotor: education and rehabilitation. 2. ed. Blumenau: Manole, 2000.

11. Tavares MCC. Body Image: Concept and development. Barueri: Manole, 2003

12. Trindade RS. Available in http://www.cbcm.com.br/modulos/ artigos/descricao .php? Cod = 28. Access 05.06.2016.

13. APA: American PsychiatricAssociation. Diagnostic and Statistical Manual of Mental Disorders. 4th ed. DSM-IV. Trad. Dayse Batista. Porto Alegre: Medical Arts, 1994.

14. Dhossche $D$, Rubinstein J. Drug detection in asuburban psychotic emergency room.Annalsof Clinic Psychiatry, v.8, n.2, p.59-69, 1996.

15. Giancola PR. Irritability, acute alcohol consumption and aggressive behavior in men and women. Drug and Alcohol Dependence, v.68, p.263-274, 2002.

16. Ferreira CAM, Thompson R. Imagem e esquema corporal. São Paulo: Lovise, 2002.

17. Askevold F. Measuring body image.Psycoter.Psychosom. v. 26, 1975, p. 71-7.

18. Lyvers M. Loss of control in alcoholism and drug addiction: a neuroscientific interpretation. Experience and Clinical Psychopharmacology, v. 8, 225-249, 2000.

19. Biggins CA, Mackay S, Clark W, Fein G. Event-related potential evidence for frontal cortex effects of chronic cocaine dependence. Society of Biological Psychiatry, v.42, p.472-485, 1997.

20. Volkow ND, Ding Y, Fowler JS, Wang G. Cocaine addiction: hypothesis derived from imaging studies with PET. Journal of Addictive Diseases, v.15, p.55-71, 1996.
21. Moeller FG, Dougherty DM, Barrat ES, Oderinde V, Mathias CW, Harper RA, Swann AC. Increased impulsivity in cocaine dependent subjects independent of antisocial personality disorder and aggression. Drug and Alcohol Dependence, v.68, p.105- 111, 2002

22. Fein G, Sclafani V, Meyerhoff DJ. Prefrontal cortical with frontal cortex volume reduction associated function deficit in 6-weekabstinent crack cocaine dependent men. Drugs and Alcohol Dependence, v.68, p.87-95, 2002.

23. Amann-Gainotti M. (1988). La rappresentazione dell'interno del corpo: Uno studio evolutivo. Archvio di Psicologia Neurolgia Psichiatria, 4, 480-496.

24. Souza SL. Monograph Undergraduate Physiotherapy. Comparative Study of Body Perception of the Student of $1^{\circ}$ and $8^{\circ}$ Physiotherapy Period via Askevold method. Patos-PB 2010.

25. Sonstroem JR, Morgan WP. (1989). Exercise and self-esteem: rationale and model. Medicine and Science in Sports and Exercise, 21 (3): 329-37.

26. Loland NW. (1998). Body image and physical activity: a survey Among Norwegian men and women. International Journal of Sport Psychology, 29, 339-363.
Publish in International Archives of Medicine

International Archives of Medicine is an open access journal publishing articles encompassing all aspects of medical science and clinical practice. IAM is considered a megajournal with independent sections on all areas of medicine. IAM is a really international journal with authors and board members from all around the world. The journal is widely indexed and classified Q2 in category Medicine. 